\title{
Body weight and body shape concerns and related behaviours among Indian urban adolescent girls
}

\author{
Nivedita Som and Susmita Mukhopadhyay* \\ Indian Statistical Institute, Biological Anthropology Unit, 203 Barrackpore Trunk Road, Kolkata 700108, India
}

Submitted 20 June 2013: Final revision received 23 May 2014: Accepted 15 June 2014: First published online 31 July 2014

\begin{abstract}
Objective: To assess the associations of body weight and body shape concerns and related behaviours with actual weight status among urban adolescent girls.

Design: In the present cross-sectional study, a self-administered questionnaire was used to collect data on body weight and body shape concerns and related behaviours. Sociodemographic information was collected using a pre-tested schedule. Weight and height of each girl were measured to assess actual weight status.

Setting: Twin cities of Kolkata and Howrah, West Bengal, India.

Subjects: A total of 1223 adolescent girls aged 14-19 years were selected from nine schools in Kolkata and Howrah in West Bengal.

Results: Many overweight girls perceived themselves as overweight and engaged in weight-reducing activities. However, several normal-weight girls also perceived them as overweight and attempted to lose weight. Unhealthy eating practices to reduce weight were followed by both overweight and normal-weight girls and even by a few underweight girls. Multivariate binary logistic regression showed a significant association between actual weight status and use of unhealthy weightloss measures. The likelihood of adopting unhealthy eating practices was significantly higher among overweight than normal-weight girls.

Conclusions: Health education programmes should be introduced at schools to promote effective weight-control practices that help dispel myths about weight loss.
\end{abstract}

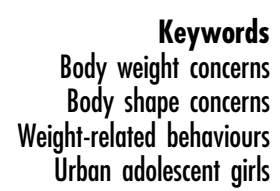

Body weight concerns Body shape concerns Urban adolescent girls
Adolescence is a critical period of life characterised by rapid growth and development, both physically and psychologically ${ }^{(1,2)}$. Changes in physical appearance make adolescents, particularly girls, self-conscious about their bodies ${ }^{(3-5)}$. Body image conception of an individual may or may not match with the objective reality. As a consequence, in spite of being within a healthy weight range, a girl may become seriously concerned about her body weight and shape ${ }^{(6-8)}$. Western societies introduce the concept of a slim and slender body for females as the symbol of physical attractiveness and beauty. This concept seems to develop dissatisfaction with body weight and shape among adolescent girls ${ }^{(9,10)}$. Preoccupation with thinness enhances weight-related stigmas and subsequent eating concerns among girls ${ }^{(11-13)}$. The impact of this socially stereotyped thin body image is largely promoted by the pervasiveness of mass media ${ }^{(14-17)}$. Additionally, mothers' encouragement towards girls' weight-loss attitudes and mothers' own eating practices ${ }^{(18-20)}$ and peer influences ${ }^{(21,22)}$ become the major forces of motivation for adopting weight-reducing eating habits among girls.
The rising incidence of obesity among adolescent girls develops a discrepancy between their body image perception and cultural expectations ${ }^{(23,24)}$. As a result, overweight and obese girls show greater risk of weightrelated physical and psychosocial consequences ${ }^{(24,25)}$ and adopt a variety of weight-reducing eating habits ${ }^{(26)}$. They are more likely to follow unhealthy eating practices (like binging, skipping meals, starving for the whole day, use of laxatives and diet pills) rather than healthy eating practices (like consumption of nutritious foods, reduction of fat intake $)^{(27,28)}$. The major public health concern centres on the fact that not only overweight girls but also normalweight and underweight girls follow unhealthy weightreducing measures, with a desire to be thin. Misconception about body weight also prevails among them, irrespective of their weight status ${ }^{(29)}$.

Concerns about weight and eating practices are also reported for African and Asian adolescents ${ }^{(30-34)}$. Unhealthy eating attitudes are found to be common among South African schoolgirls of different ethnic backgrounds ${ }^{(30)}$. Studies in South Asian countries reveal that 
girls, irrespective of their weight status, follow beauty standards of Western cultures; however, their eating behaviours fail to show significant differences ${ }^{(31,34)}$.

In India, with the advent of modernisation, eating and weight concerns are increasing alarmingly among urban adolescent girls as a consequence of the rising incidence of body fat, although a plump body shape is preferred in traditional Indian culture. A few studies show that Indian adolescent girls express a milder form of weight dissatisfaction with added extreme fear of fatness ${ }^{(35)}$ and subsequently attempt to achieve a slim and trim body shape by following various weight-loss measures ${ }^{(36-38)}$. Therefore, it seems that unhealthy weight-related behaviours seriously affect their physical and mental abilities at this vulnerable phase of growth ${ }^{(39)}$. With this backdrop, the present study aims to examine the associations of body weight and body shape concerns and related behaviours with actual weight status among urban adolescent girls.

\section{Materials and methods}

\section{Study area}

The present cross-sectional study was conducted in the twin cities of Kolkata and Howrah, districts of West Bengal, located in the eastern part of India.

\section{Study population}

Initially, a list of 100 schools for girls within the study area was prepared. Out of these, forty schools were chosen randomly and approached for permission. Only nine $(22.5 \%)$ schools granted permission to conduct the survey. A total of 1445 girls were enlisted following the complete enumeration method from grades 9 to 12 of those selected nine schools. Of them, 1223 girls were finally selected on the basis of the sole inclusion criterion, i.e. age (14-19 years). Among those ( $n$ 222) who could not participate, $20 \%$ were outside the age range, while $33 \%$ were not present during the time of survey and the rest (37\%) did not receive parental consent (Fig. 1). Written informed consent was obtained from the principal of each school and the parent of each participating girl prior to the study, while verbal assent was obtained from each of the girls participating in the survey. The data were collected during February 2011 to December 2012. Overall study objectives, methods and instruments used were reviewed and approved by the Institutional Review Board of the Indian Statistical Institute.

\section{Data collection}

\section{Sociodemographic measures}

Data on the age of the girls, education level and occupation type of both parents and monthly household expenditure were collected using a pre-tested schedule.

\section{Anthropometric data and weight status}

Height and weight of the adolescent girls were measured by one of the authors (N.S.). Height was measured to the nearest of $0.1 \mathrm{~cm}$ using a portable GPM anthropometer and weight was measured to the nearest of $0.1 \mathrm{~kg}$ for each participant in light clothing without shoes using a Tanita digital scale (Tanita-TBF-521). BMI was calculated using the formula: $\mathrm{BMI}=[$ weight $(\mathrm{kg})] /[\text { height }(\mathrm{m})]^{2}$. Calculated BMI was translated into an age- and sex-specific BMI $Z$-score using the cut-off points based on reference data from the $\mathrm{WHO}^{(40)}$. Girls were categorised as underweight/thin (BMI-for-age $Z$-score $<-2$ ), normal weight (BMI-for-age $Z$-score of -2 to 1 ), overweight (BMI-for-age $Z$-score of 1 to 2 ) and obese (BMI-for-age $Z$-score $>2$ ). The few obese girls (with BMI-for-age $Z$-score $>2$ ) were combined with overweight girls to make the 'overweight group'.

\section{Measures of body weight and body shape concerns and related behaviours}

Body weight and body shape concerns and related behaviours were assessed with a self-administered questionnaire, adapted and slightly modified from the questionnaires used in other studies ${ }^{(27,32,41)}$. The original version of the questionnaire was in English. Since Bengali is the vernacular language of the study population, it was translated into Bengali and back-translated into English for validation by professional translators. This self-administered questionnaire included twenty-two questions, each with dichotomous response choices (Table 1 ).

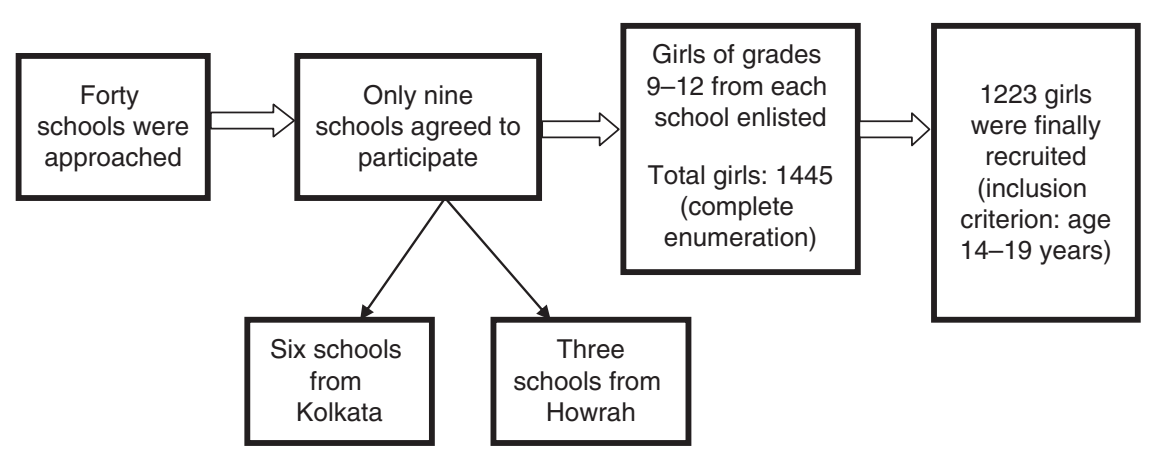

Fig. 1 Flowchart showing the enrolment of girls in the present study 
Table 1 Body weight and body shape concerns and related behaviours

\begin{tabular}{l}
\hline Question \\
\hline Body weight perception \\
Perceive yourself as underweight (yes/no) \\
Perceive yourself as normal weight (yes/no) \\
Perceive yourself as overweight (yes/no) \\
Body weight dissatisfaction (yes/no) \\
Body shape perception \\
Perceive as thin (yes/no) \\
Perceive as fat (yes/no) \\
Worry about \\
Being thin (yes/no) \\
Being fat (yes/no) \\
Attempt to lose weight (yes/no) \\
Attempt to gain weight (yes/no) \\
Use of weight-loss measures \\
Eating fewer foods than required (yes/no) \\
Exercise vigorously (yes/no) \\
Skipping meals (yes/no) \\
Fasting (yes/no) \\
Using food supplements (yes/no) \\
Reducing fat intake (yes/no) \\
Eating more fruits and vegetables (yes/no) \\
Use of weight-gain measures \\
Eating larger portions of foods (yes/no) \\
Exercise moderately (yes/no) \\
Eating more meals in a day (yes/no) \\
Using food supplements (yes/no) \\
Eating more fatty foods (yes/no) \\
\hline
\end{tabular}

\section{Data analysis}

Data were analysed using the statistical software package IBM SPSS Statistics for Windows, version 20. Descriptive statistics (frequency and percentage) were computed to understand the trends in sociodemographic profile of the participating girls. The $\chi^{2}$ test was used to show the association of actual weight status with each of the variables considered for body weight and body shape concerns and related behaviours. Multivariate binary logistic regression (stepwise) was carried out for each of the variables designed for body weight and body shape concerns and its related behaviours to show the association with actual weight status of the girls after adjusting for the effects of sociodemographic variables. Actual weight status of the girls and other sociodemographic variables (age of the girls, education level and occupation type of both parents, monthly household expenditure) were included as covariates in each model. Each of the variables considered for body weight and body shape concerns and related behaviours was incorporated as a dependent variable for each separate model. However, several weight-loss measures (eating more fruits and vegetables, reducing fat intake, fasting, using food supplements) and only one weight-gain measure (eating more fatty foods) were not used as dependent variables as their response rate was low. Before performing regression analyses, a multiple imputation method was applied to replace the missing values in the sociodemographic variables (education level and occupation type of both parents, monthly household expenditure). Each of the sociodemographic variables (except age of the girls) was converted into dummy variables. A $P$ value of $\leq 0.05$ was considered statistically significant and only significant predictor variables are presented with odds ratio and 95\% confidence interval. Weighted $\kappa$ with $95 \%$ confidence interval was calculated to understand the degree of agreement between perception and self-categorization of weight status. A $\kappa$ of 0.41-0.60 indicates 'moderate' agreement ${ }^{(42)}$. Sensitivity and specificity of self-judgement of overweight status against actual weight status were also measured. The Kuder Richardson index-20 was calculated to judge the reliability of the questionnaire and the tested value was $0 \cdot 73$, which indicated that the test result proved to be acceptable.

\section{Results}

\section{Sociodemographic profile}

The study initially included 1445 girls from a wide range of sociodemographic profiles. The total response rate was $84.6 \%$. Table 2 portrays the sociodemographic profile of the girls. Most of the girls were aged between 14 and 15 years $(52.3 \%)$ and belonged to a family with monthly household expenditure of Rs 8000-20000 (43.4\%). Parents' attained education was mostly below the graduation level (fathers, 50.3\%; mothers, 62.5\%). More than $80 \%$ of mothers were home makers and fathers were mostly $(65.6 \%)$ in service.

\section{Body weight and body shape concerns and actual weight status of girls}

Table 3 shows that most of the girls perceived their weight status in accordance with their actual weight status, although exceptions were also noticed. For example, $39.7 \%$ of underweight girls misperceived themselves as of normal weight; $1.3 \%$ of underweight girls and $10.7 \%$ of normal-weight girls misperceived themselves as overweight. Most of the overweight girls were found to be dissatisfied with their present weight status. However, a substantial proportion of normal-weight and underweight girls were found to be happy with their actual weight status. Actual weight status showed significant associations with body weight and body shape perception, body weight dissatisfaction and distress regarding body shape. A high percentage $(78.8 \%)$ of overweight girls perceived themselves as fat and also expressed distress (74.6\%) regarding their fatness. Additionally, several normalweight girls (29.5\%) and a few underweight girls (3.8\%) failed to show proper perception regarding their body shape. They inaccurately reported themselves as fat. More than $30 \%$ of normal-weight girls and $10 \cdot 3 \%$ of underweight girls also expressed fear of becoming fat. 
Table 2 Sociodemographic profile of the adolescent girls, Kolkata and Howrah, West Bengal, India, February 2011-December 2012

\begin{tabular}{|c|c|c|c|c|}
\hline Sociodemographic variable & & & $n$ & $\%$ \\
\hline \multicolumn{5}{|l|}{ Age group (years) ( $n$ 1223) } \\
\hline $14-15$ & & & 639 & $52 \cdot 3$ \\
\hline $16-17$ & & & 452 & $37 \cdot 0$ \\
\hline $18-19$ & & & 132 & $10 \cdot 7$ \\
\hline \multicolumn{5}{|c|}{ Monthly household expenditure (Rs) ( $n$ 737) } \\
\hline$<8000$ & & & 312 & $42 \cdot 3$ \\
\hline $8000-20000$ & & & 320 & $43 \cdot 4$ \\
\hline \multirow[t]{2}{*}{$>20000$} & & & 105 & $14 \cdot 2$ \\
\hline & \multicolumn{2}{|c|}{ Father ( $n$ 853) } & \multicolumn{2}{|c|}{ Mother $(n 876)$} \\
\hline Education level of parents & $n$ & $\%$ & $n$ & $\%$ \\
\hline Below graduate & 429 & $50 \cdot 3$ & 548 & 62.5 \\
\hline Graduate & 346 & 40.5 & 273 & $31 \cdot 2$ \\
\hline \multirow{2}{*}{ Above graduate } & 78 & $9 \cdot 1$ & 55 & $6 \cdot 3$ \\
\hline & \multicolumn{2}{|c|}{ Father ( $n$ 883) } & \multicolumn{2}{|c|}{ Mother $(n$ 1167) } \\
\hline Occupation type of parents & $n$ & $\%$ & $n$ & $\%$ \\
\hline Home maker & - & - & 1013 & $86 \cdot 8$ \\
\hline Service & 579 & $65 \cdot 6$ & 110 & 9.4 \\
\hline Professional & 51 & $5 \cdot 7$ & 14 & 1.2 \\
\hline Business & 231 & $26 \cdot 2$ & 18 & 1.5 \\
\hline Others & 22 & $2 \cdot 5^{\star}$ & 12 & $1 \cdot 1 \dagger$ \\
\hline
\end{tabular}

Rs, Indian rupees.

${ }^{*}$ Others: private tutor, pension holder.

†Others: maid servant, private tutor.

Table 3 Body weight and body shape concerns according to actual weight status among the adolescent girls ( $n$ 1223), Kolkata and Howrah, West Bengal, India, February 2011-December 2012

\begin{tabular}{|c|c|c|c|c|c|c|c|}
\hline \multirow[b]{3}{*}{ Body weight and body shape concerns } & \multicolumn{6}{|c|}{ Actual weight status (based on BMI-for-age Z-score) } & \multirow{3}{*}{$\underset{P \text { value }}{X^{2}}$} \\
\hline & \multicolumn{2}{|c|}{ Underweight $(n 78)$} & \multicolumn{2}{|c|}{ Normal weight $(n 787)$} & \multicolumn{2}{|c|}{ Overweight ( $n$ 358) } & \\
\hline & $n$ & $\%$ & $n$ & $\%$ & $n$ & $\%$ & \\
\hline \multicolumn{8}{|l|}{ Body weight perception } \\
\hline Underweight & 46 & $59 \cdot 0$ & 121 & $15 \cdot 4$ & 4 & $1 \cdot 1$ & \multirow{3}{*}{$\begin{array}{c}463.92 \\
P<0.001\end{array}$} \\
\hline Normal weight & 31 & $39 \cdot 7$ & 582 & 74.0 & 143 & 39.9 & \\
\hline Overweight & 1 & 1.3 & 84 & $10 \cdot 7$ & 211 & 58.9 & \\
\hline \multicolumn{8}{|l|}{ Body weight dissatisfaction } \\
\hline No & 63 & $80 \cdot 8$ & 700 & 88.9 & 192 & $53 \cdot 6$ & \multirow{2}{*}{$\begin{array}{c}179.68 \\
P<0.001\end{array}$} \\
\hline Yes & 15 & $19 \cdot 2$ & 87 & $11 \cdot 1$ & 166 & $46 \cdot 4$ & \\
\hline \multicolumn{8}{|l|}{ Body shape perception } \\
\hline Thin & 64 & $82 \cdot 1$ & 378 & $48 \cdot 0$ & 38 & $10 \cdot 6$ & \multirow{2}{*}{$\begin{array}{c}275.54 \\
P<0.001\end{array}$} \\
\hline Fat & 3 & $3 \cdot 8$ & 232 & 29.5 & 282 & $78 \cdot 8$ & \\
\hline \multicolumn{8}{|l|}{ Worry about } \\
\hline Being thin & 43 & $55 \cdot 1$ & 128 & $16 \cdot 3$ & 9 & 2.5 & \multirow{2}{*}{$\begin{array}{c}178.77 \\
P<0.001\end{array}$} \\
\hline Being fat & 8 & $10 \cdot 3$ & 247 & 31.4 & 267 & 74.6 & \\
\hline
\end{tabular}

Body weight-and body shape-related behaviours and actual weight status of girls

Body weight- and body shape-related behaviours of the adolescent girls with respect to their actual weight status are documented in Table 4. The majority of overweight and normal-weight girls were found to engage in weightreducing activities. However, underweight girls mostly attempted to gain weight. Girls followed several measures to lose weight, which could be categorised as both healthy and unhealthy. Healthy measures, such as vigorous physical exercise, consumption of fruits and vegetables and reduced fat intake, were followed by $3.8 \%$ of underweight, $17.9 \%$ of normal-weight and 39.9\% of overweight girls. Similarly, unhealthy measures, such as fasting, eating fewer foods than required, skipping meals and using food supplements, were found to be adopted by $5.1 \%$ of underweight, $29.4 \%$ of normal-weight and $69.8 \%$ of overweight girls. On the other hand, underweight girls mostly followed healthy weightgain measures such as eating larger portions of foods (51.3\%), moderate physical exercise ( $9.0 \%)$, eating more meals in a day (11.5\%) and use of food supplements $(16 \cdot 7 \%)$. Girls attempted to gain weight mostly by eating larger portions of foods. Physical exercise was the least adopted healthy activity among them. 
Table 4 Body weight- and body shape-related behaviours according to actual weight status among the adolescent girls ( $n$ 1223), Kolkata and Howrah, West Bengal, India, February 2011-December 2012

\begin{tabular}{|c|c|c|c|c|c|c|c|}
\hline \multirow[b]{3}{*}{ Body weight- and body shape-related behaviours } & \multicolumn{6}{|c|}{ Actual weight status (based on BMI-for-age- $Z$ score) } & \multirow{3}{*}{$\stackrel{x^{2}}{P \text { value }}$} \\
\hline & \multicolumn{2}{|c|}{ Underweight $(n 78)$} & \multicolumn{2}{|c|}{ Normal weight $(n 787)$} & \multicolumn{2}{|c|}{ Overweight (n 358) } & \\
\hline & $n$ & $\%$ & $n$ & $\%$ & $n$ & $\%$ & \\
\hline \multicolumn{8}{|l|}{ Attempt to } \\
\hline Lose weight & 4 & $5 \cdot 1$ & 246 & $31 \cdot 3$ & 269 & $75 \cdot 1$ & 217.58 \\
\hline Gain weight & 44 & $56 \cdot 4$ & 159 & $20 \cdot 2$ & 3 & 0.8 & $P<0.001$ \\
\hline \multicolumn{8}{|l|}{ Weight-loss measures } \\
\hline \multicolumn{8}{|l|}{ Healthy measures } \\
\hline Exercise vigorously & 3 & 3.8 & 132 & $16 \cdot 8$ & 133 & $37 \cdot 2$ & \\
\hline Eating more fruits and vegetables & - & - & 6 & 0.8 & 6 & 0.02 & \\
\hline Reducing fat intake & _ & - & 3 & 0.4 & 4 & 0.01 & 0.26 \\
\hline Unhealthy measures & & & & & & & $P=0.876$ \\
\hline Eating fewer foods than required & 3 & 3.8 & 193 & 24.5 & 208 & $58 \cdot 1$ & \\
\hline Fasting & - & - & 5 & 0.6 & 4 & 1.1 & \\
\hline Skipping meals & 1 & 1.3 & 30 & 3.8 & 33 & 9.2 & \\
\hline Using food supplements & - & - & 4 & 0.5 & 5 & 1.4 & \\
\hline \multicolumn{8}{|l|}{ Weight-gain measures } \\
\hline \multicolumn{8}{|l|}{ Healthy measures } \\
\hline Eating larger portions of foods & 40 & 51.3 & 126 & $16 \cdot 0$ & 5 & $1 \cdot 4$ & \\
\hline Exercise moderately & 7 & 9.0 & 22 & $2 \cdot 8$ & 2 & 0.6 & \\
\hline Eating more meals in a day & 9 & 11.5 & 39 & $5 \cdot 0$ & 1 & 0.3 & \\
\hline Using food supplements & 13 & $16 \cdot 7$ & 46 & $5 \cdot 8$ & 1 & 0.3 & \\
\hline Unhealthy measures & & & & & & & $-^{*}$ \\
\hline Eating more fatty foods & - & - & 2 & 0.3 & - & - & \\
\hline
\end{tabular}

${ }^{\star}$ The $x^{2}$ test was not performed due to the presence of two cells with zero value in the variable considered for unhealthy measures.

\section{Multivariate analyses}

In Table 5, results of multivariate binary logistic regression analyses (stepwise) reveal that after adjusting for sociodemographic factors, actual weight status of the girls significantly predicted all of the variables considered for body weight and body shape concerns. As compared with normal-weight girls, overweight girls were more likely to perceive themselves as overweight and fat, be dissatisfied with body weight and express fear of becoming fat. Similarly, the likelihood of showing concerns over body weight and shape was significantly higher for underweight girls compared with their normal-weight counterparts. Weight-related behaviours of the girls were found to be significantly predicted by their actual weight status after adjusting for the effects of sociodemographic factors (Table 6). The association between actual weight status and unhealthy eating practices was significant. Overweight girls were more likely to report weight-reducing attitudes and to follow several weight-loss measures. Underweight girls tended to follow several weight-gain measures. This relationship remained statistically significant in multivariate analysis.

\section{Agreement between actual and perceived body weight status of girls}

A weighted $\kappa$ value of 0.52 in Table 7 indicates that there was moderate agreement between actual and perceived body weight status of the girls. We also examined the sensitivity and specificity of self-judgement of overweight status against actual weight status. The sensitivity was moderately high, indicating that actual overweight girls (58.9\%) truly judged themselves as overweight. The specificity value was remarkably higher, indicating that more than $90 \%$ of non-overweight girls correctly identified their weight status. With moderate sensitivity and high specificity value, the test result proved to be good.

\section{Discussion}

The present cross-sectional study attempts to evaluate the associations of body weight and body shape concerns and related behaviours among a group of urban adolescent girls with their actual weight status. The present findings suggest that body weight and body shape concerns and related behaviours are largely associated with the actual weight status of these girls. Overweight girls are more likely to report use of several weight-loss strategies along with the prime concerns over body weight and shape compared with their normal-weight and underweight counterparts.

The number of overweight girls in both developed and developing countries is increasing steadily ${ }^{(43-45)}$. Consequently, an urge to be thin following several weightreducing practices has become an increasing trend among overweight youth $^{(38,46)}$. These weight-reducing behaviours sometimes involve the use of several unhealthy measures $^{(29,46)}$. In our study, concerns over body weight and shape and the practice of weight-related behaviours are prevalent among overweight girls. Less than three-fifths of 
Table 5 Multivariate binary logistic regression analyses (stepwise) using each of the variables considered for body weight and body shape concerns as a dependent variable; adolescent girls ( $n$ 1223), Kolkata and Howrah, West Bengal, India, February 2011-December 2012

\begin{tabular}{|c|c|c|c|c|c|}
\hline \multirow[b]{2}{*}{ Dependent variable(s) } & \multirow[b]{2}{*}{ Predictor variable(s) } & \multirow[b]{2}{*}{ OR } & \multirow[b]{2}{*}{$P$ value } & \multicolumn{2}{|c|}{$95 \% \mathrm{Cl}$ for OR } \\
\hline & & & & Lower & Upper \\
\hline \multirow[t]{5}{*}{ Perceived as underweight } & $\begin{array}{l}\text { Actual weight status } \\
\text { Normal weight }\end{array}$ & Ref. & & & \\
\hline & Underweight & 7.72 & $<0.001$ & 4.71 & $12 \cdot 65$ \\
\hline & $\begin{array}{l}\text { Overweight } \\
\text { Monthly household expenditure (Rs) }\end{array}$ & 0.06 & $<0.001$ & 0.02 & 0.17 \\
\hline & $<8000$ & Ref. & & & \\
\hline & $>20000$ & 0.43 & 0.019 & 0.21 & 0.87 \\
\hline \multirow[t]{6}{*}{ Perceived as normal weight } & $\begin{array}{l}\text { Actual weight status } \\
\text { Normal weight }\end{array}$ & Ref. & & & \\
\hline & Underweight & 0.22 & $<0.001$ & 0.13 & 0.36 \\
\hline & Overweight & 0.22 & $<0.001$ & 0.17 & 0.29 \\
\hline & Age of girls & 0.87 & 0.004 & 0.80 & 0.95 \\
\hline & Occupation type of mother & & & & \\
\hline & $\begin{array}{l}\text { Others* } \\
\text { Business }\end{array}$ & $\begin{array}{l}\text { Ref. } \\
0.36\end{array}$ & 0.028 & 0.15 & 0.89 \\
\hline \multirow[t]{8}{*}{ Perceived as overweight } & Actual weight status & & & & \\
\hline & Normal weight & Ref. & & & \\
\hline & Underweight & 0.10 & 0.024 & 0.01 & 0.73 \\
\hline & Overweight & 12.99 & $<0.001$ & 9.45 & 17.86 \\
\hline & Age of girls & $1 \cdot 17$ & 0.004 & 1.05 & 1.31 \\
\hline & Occupation type of mother & & & & \\
\hline & Others* ${ }^{*}$ & Ref. & & & \\
\hline & Business & 3.42 & 0.018 & 1.23 & 9.52 \\
\hline \multirow[t]{5}{*}{ Body weight dissatisfaction } & Actual weight status & & & & \\
\hline & Normal weight & Ref. & & & \\
\hline & Underweight & 1.89 & 0.039 & 1.03 & 3.48 \\
\hline & Overweight & 7.37 & $<0.001$ & 5.40 & 10.04 \\
\hline & Age of girls & 1.18 & 0.002 & 1.06 & 1.31 \\
\hline \multirow[t]{10}{*}{ Perceived body shape as thin } & Actual weight status & & & & \\
\hline & Normal weight & Ref. & & & \\
\hline & Underweight & 4.88 & $<0.001$ & 2.68 & 8.87 \\
\hline & Overweight & 0.12 & $<0.001$ & 0.08 & 0.18 \\
\hline & Education level of mother & & & & \\
\hline & Below graduate & Ref. & & & \\
\hline & Above graduate & 0.43 & 0.004 & 0.24 & 0.77 \\
\hline & Occupation type of father & & & & \\
\hline & Others $\dagger$ & Ref. & & & \\
\hline & Service & 1.29 & 0.048 & 1.00 & 1.67 \\
\hline \multirow{10}{*}{ Perceived body shape as fat } & Actual weight status & & & & \\
\hline & Normal weight & Ref. & & & \\
\hline & Underweight & 0.08 & $<0.001$ & 0.02 & 0.27 \\
\hline & Overweight & $9 \cdot 29$ & $<0.001$ & 6.87 & 12.54 \\
\hline & Education level of father & & & & \\
\hline & Below graduate & Ref. & & & \\
\hline & Above graduate & 0.63 & 0.044 & 0.40 & 0.98 \\
\hline & Occupation type of mother & & & & \\
\hline & Others* ${ }^{*}$ & Ref. & & & \\
\hline & Business & 4.48 & 0.003 & 1.63 & $12 \cdot 28$ \\
\hline \multirow[t]{8}{*}{ Worried about being thin } & Actual weight status & & & & \\
\hline & Normal weight & Ref. & & & \\
\hline & Underweight & 6.93 & $<0.001$ & $4 \cdot 20$ & 11.42 \\
\hline & Overweight & 0.14 & $<0.001$ & 0.07 & 0.28 \\
\hline & Age of girls & 1.23 & 0.001 & 1.09 & 1.38 \\
\hline & Education level of father & & & & \\
\hline & Below graduate & Ref. & & & \\
\hline & Graduate & 0.51 & 0.001 & 0.34 & 0.74 \\
\hline \multirow[t]{11}{*}{ Worried about being fat } & Actual weight status & & & & \\
\hline & Normal weight & Ref. & & & \\
\hline & Underweight & 0.24 & $<0.001$ & 0.11 & 0.52 \\
\hline & Overweight & $6 \cdot 62$ & $<0.001$ & 4.97 & 8.83 \\
\hline & Education level of father & & & & \\
\hline & Below graduate & Ref. & & & \\
\hline & $\begin{array}{l}\text { Graduate } \\
\text { Occupation type of mother }\end{array}$ & 0.71 & 0.015 & 0.54 & 0.93 \\
\hline & Others ${ }^{\star}$ & Ref. & & & \\
\hline & Business & 3.57 & 0.009 & 1.37 & 9.31 \\
\hline & Monthly household expenditure (Rs) & & & & \\
\hline & $\begin{array}{l}<8000 \\
>20000\end{array}$ & $\begin{array}{l}\text { Ref. } \\
1.81\end{array}$ & 0.002 & 1.25 & 2.63 \\
\hline
\end{tabular}

Rs, Indian rupees; Ref., reference category.

*Others: maid servant, private tutor.

†Others: private tutor, pension holder. 
Table 6 Multivariate binary logistic regression analyses (stepwise) using each of the variables considered for body weight- and body shape-related behaviours as a dependent variable; adolescent girls ( $n$ 1223), Kolkata and Howrah, West Bengal, India, February 2011-December 2012

\begin{tabular}{|c|c|c|c|c|c|}
\hline \multirow[b]{2}{*}{ Dependent variable(s) } & \multirow[b]{2}{*}{ Predictor variable(s) } & \multirow[b]{2}{*}{ OR } & \multirow[b]{2}{*}{$P$ value } & \multicolumn{2}{|c|}{$95 \% \mathrm{Cl}$ for $\mathrm{OR}$} \\
\hline & & & & Lower & Upper \\
\hline \multirow[t]{6}{*}{ Attempt to lose weight } & $\begin{array}{l}\text { Actual weight status } \\
\text { Normal weight }\end{array}$ & Ref. & & & \\
\hline & Underweight & 0.11 & $<0.001$ & 0.04 & 0.32 \\
\hline & Overweight & 6.79 & $<0.001$ & $5 \cdot 10$ & 9.03 \\
\hline & Occupation type of father & & & & \\
\hline & Others* ${ }^{*}$ & Ref. & & & \\
\hline & Service & 0.77 & 0.046 & 0.59 & 0.99 \\
\hline \multirow[t]{7}{*}{ Attempt to gain weight } & Actual weight status & & & & \\
\hline & Normal weight & Ref. & & & \\
\hline & Underweight & $5 \cdot 13$ & $<0.001$ & $3 \cdot 16$ & 8.31 \\
\hline & Overweight & 0.03 & $<0.001$ & 0.01 & 0.10 \\
\hline & Education level of mother & & & & \\
\hline & Below graduate & Ref. & & & \\
\hline & Graduate & 0.66 & 0.032 & 0.45 & 0.96 \\
\hline \multicolumn{6}{|l|}{ Weight-loss measures } \\
\hline \multirow[t]{4}{*}{ Eating fewer foods than required } & Actual weight status & & & & \\
\hline & Normal weight & Ref. & & & \\
\hline & Underweight & 0.12 & $<0.001$ & 0.03 & 0.39 \\
\hline & Overweight & 4.26 & $<0.001$ & 3.27 & 5.56 \\
\hline \multirow[t]{7}{*}{ Exercise vigorously } & Actual weight status & & & & \\
\hline & Normal weight & Ref. & & & \\
\hline & Underweight & 0.19 & 0.007 & 0.06 & 0.64 \\
\hline & Overweight & $2 \cdot 82$ & $<0.001$ & $2 \cdot 12$ & 3.76 \\
\hline & Education level of mother & & & & \\
\hline & Below graduate & Ref. & & & \\
\hline & Graduate & 1.57 & 0.002 & 1.17 & $2 \cdot 10$ \\
\hline \multirow[t]{7}{*}{ Skipping meals } & Actual weight status & & & & \\
\hline & Normal weight & Ref. & & & \\
\hline & Overweight & 2.85 & $<0.001$ & 1.70 & 4.78 \\
\hline & Age of girls & 1.27 & 0.008 & 1.06 & 1.52 \\
\hline & Education level of mother & & & & \\
\hline & Below graduate & Ref. & & & \\
\hline & Above graduate & $3 \cdot 13$ & 0.002 & 1.54 & $6 \cdot 36$ \\
\hline \multicolumn{6}{|l|}{ Weight-gain measures } \\
\hline \multirow{5}{*}{ Eating larger portions of foods } & Actual weight status & & & & \\
\hline & Normal weight & Ref. & & & \\
\hline & Underweight & 5.54 & $<0.001$ & 3.41 & 9.01 \\
\hline & Overweight & 0.07 & $<0.001$ & 0.03 & 0.18 \\
\hline & Age of girls & $1 \cdot 15$ & 0.020 & 1.02 & 1.30 \\
\hline \multirow[t]{4}{*}{ Exercise moderately } & Actual weight status & & & & \\
\hline & Normal weight & Ref. & & & \\
\hline & Underweight & 3.42 & 0.006 & 1.41 & 8.30 \\
\hline & Overweight & 0.19 & 0.028 & 0.04 & 0.83 \\
\hline \multirow{4}{*}{ Eating more meals in a day } & Actual weight status & & & & \\
\hline & Normal weight & Ref. & & & \\
\hline & Underweight & $2 \cdot 34$ & 0.030 & 1.08 & 5.06 \\
\hline & Overweight & 0.05 & 0.050 & 0.01 & 0.42 \\
\hline
\end{tabular}

Ref., reference category.

*Others: private tutor, pension holder.

Table 7 Estimated sensitivity, specificity and weighted $k$ for agreement between body weight perception and actual weight status of adolescent girls ( $n$ 1223), Kolkata and Howrah, West Bengal, India, February 2011-December 2012

\begin{tabular}{lcccr}
\hline Perceived weight status & Sensitivity (\%) & Specificity $(\%)$ & Weighted $\kappa$ & $95 \% \mathrm{Cl}$ \\
\hline $\begin{array}{l}\text { Underweight }(n 78) \\
\begin{array}{l}\text { Normal weight }(n \text { 787) } \\
\text { Overweight }(n \text { 358) }\end{array}\end{array}$ & 90.17 & 58.93 & 0.52 & $0.47,0.56$ \\
\hline
\end{tabular}

overweight girls rightly perceive themselves as overweight and the rest mostly misperceive themselves as normal weight. A large number of overweight girls express dissatisfaction with body weight and shape. Earlier studies show that rates of adopting weight-reducing strategies are high among overweight girls compared with their 
non-overweight counterparts ${ }^{(38,46)}$. These findings are consistent with our results. It could be an indication of either their perception of being normal weight or their perceived hopelessness towards weight reduction. These overweight girls are mostly engaged in unhealthy eating practices of reducing body weight other than physical exercise. A combination of these, i.e. healthy food habits and adequate physical exercise, would have been an ideal measure of weight reduction for them.

Our study shows that most of the normal-weight girls perceive their weight status accurately, although a few of them express dissatisfaction with body weight. They are more concerned about fat body shape rather than body weight. In order to reduce body weight, this group is also shown to follow more unhealthy measures (in terms of foods and activities) than healthy ones. Therefore, it seems that normal-weight girls are motivated to achieve a thin body shape and they decide to follow harmful steps towards the goal. One longitudinal study in the USA shows that improper eating behaviours are positively associated with rapid weight gain instead of weight loss ${ }^{(47)}$. Interestingly, weight-related misconception is found to be common among the girls who are actually underweight. These girls perceive themselves to be of normal weight, but a few remain distressed with body shape. Incidentally, this group of underweight girls is mostly shown to follow healthy weight-gain measures, although a few of them are engaged in unhealthy eating practices.

Strengths of the present study include a large study population that allows more generalisation and contributes to the current body of literature. Anthropometric measurements on height and weight for each girl account for another study strength. Self-reported behaviours including use of both weight-loss and weight-gain measures show variability of the data. The data on body weight and body shape concerns and related behaviours from a unique study group with varied sociodemographic characteristics possibly add a dimension to look into the issue. One of the limitations of the study is its crosssectional nature that fails to study the effects of change over time in the concerns and behaviours related to body weight and body shape for the same individual. In addition, adolescents may distort their weight concerns and behaviours by either under-reporting or over-reporting.

\section{Conclusion}

It is evident from the present study that Indian adolescent girls are involved in the whirlpool of body weight- and shape-related dilemmas following their Western counterparts. To achieve the desired weight status and body shape they often are caught in the web of ignorance and myths and subsequently develop unhealthy eating practices. Adoption of several weight-reduction behaviours by adolescent girls becomes matter of concern when merely out of fear of getting obese; both normal-weight and underweight girls follow this path. Therefore, the potential threats of both long-term and short-term outcomes of unhealthy eating behaviours demand serious attention for adolescent girls. Findings suggest that health education programmes should be adopted by schools to promote strategies on appropriate weight-control practices that help dispel the myths about weight loss.

\section{Acknowledgements}

Acknowledgements: The authors would like to express their gratitude to the study participants and the schools that participated in the study. They are most thankful to Dr Sharon R. Williams (Assistant Professor in the Department of Anthropology, Purdue University) and Dr Gillian H. Ice (Associate Professor of Social Medicine and Director of Global Health in the Department of Social Medicine and Office of Global Health, Ohio University) for improving the language of the manuscript. They are also thankful to Dr Sourav Ghosh and Baidyanath Pal of the Indian Statistical Institute in Kolkata for their valuable comments during the analyses of data. Financial support: The study was supported by a grant from the Indian Statistical Institute. The Indian Statistical Institute had no role in the design of the study, analysis of the data or writing of this article. Conflict of interest: None. Authorship: Both the authors were responsible for the set up of the study, analyses and interpretation of the data and writing of the manuscript. Data collection was done mostly by N.S. Ethics of buman subject participation: Overall study objectives, methods and protocols used in the study were reviewed and approved by the Institutional Review Board of the Indian Statistical Institute.

\section{References}

1. Tanner JM (1962) Growth at Adolescence, 2nd ed. Oxford: Blackwell Scientific.

2. Eccles JS (1999) The development of children ages 6 to 14. Future Child 9, 30-44.

3. Rand CS, Resnick JL \& Seldman RS (1997) Assessment of socially acceptable body sizes by university students. Obes Res 5, 425-429.

4. Siegel JM, Yancey AK, Aneshensel CS et al. (1999) Body image, perceived pubertal timing and adolescent mental health. J Adolesc Health 25, 155-165.

5. Vilhjalmsson R, Kristjansdottir G \& Ward DS (2012) Bodily deviations and body image in adolescence. Youth Soc $\mathbf{4 4}$, 366-384.

6. Jovanovic J, Lerner RM \& Lerner JV (1989) Objective and subjective attractiveness and early adolescent adjustment. J Adolesc 12, 225-229.

7. Rosenblum GD \& Lewis M (1999) The relations among body image, physical attractiveness and body mass in adolescence. Child Dev 70, 50-64.

8. Weinshenker N (2002) Adolescence and body image. School Nurse News 19, 12-16. 
9. Garner DM, Garfinkel PE, Schwartz D et al. (1980) Cultural expectations of thinness in women. Psychol Rep 47, 483-491.

10. Wiseman CV, Gray JJ, Mosimann JE et al. (1992) Cultural expectations of thinness in women: an update. Int $J$ Eat Disord 11, 85-89.

11. Bruch H (1962) Perceptual and conceptual disturbances in anorexia nervosa. Psychosom Med 24, 187-194.

12. Stice E, Nemeroff $C$ \& Shaw H (1996) Test of the dual pathway model of bulimia nervosa: evidence for dietary restraint and affect regulation mechanisms. J SOC Clin Psychol 15, 340-363.

13. Grigg M, Bowman J \& Redman S (1996) Disordered eating and unhealthy weight reduction practices among adolescent females. Prev Med 25, 748-756.

14. Tiggemann M \& Pickering AS (1996) Role of television in adolescent women's body dissatisfaction and drive for thinness. Int J Eat Disord 20, 199-203.

15. Field AE, Camargo CA, Taylor CB et al. (1999) Relation of peer and media influences to the development of purging behaviours among preadolescent and adolescent girls. Arch Pediatr Adolesc Med 153, 1184-1189.

16. Borzekowski DL, Robinson TN \& Killen JD (2000) Does the camera add 10 pounds? Media use, perceived importance of appearance, and weight concerns among teenage girls. $J$ Adolesc Health 26, 36-41.

17. Becker AE, Burwell RA, Herzog DB et al. (2002) Eating behaviours and attitudes following prolonged exposure to television among ethnic Fijian adolescent girls. $\mathrm{Br} J$ Psychiatry 180, 509-514.

18. Pike KM \& Rodin J (1991) Mothers, daughters and disordered eating. J Abnorm Psychol 100, 198-204.

19. Cooley E, Toray T, Wang MC et al. (2008) Maternal effects on daughters' eating pathology and body image. Eat Behav 9, 52-61.

20. Cromley T, Neumark-Sztainer D, Story M et al. (2010) Parent and family associations with weight-related behaviors and cognitions among overweight adolescents. J Adolesc Health 47, 263-269.

21. Vincent MA \& McCabe MP (2000) Gender differences among adolescents in family and peer influences on body dissatisfaction, weight loss and binge eating behaviours. J Youth Adolesc 29, 205-221.

22. Lieberman M, Gauvin L, Bukowski WM et al. (2001) Interpersonal influence and disordered eating behaviours in adolescent girls: the role of peer modelling, social reinforcement and body related teasing. Eat Behav 2, 215-236.

23. Paxton SJ, Eisenberg ME \& Neumark-Sztainer D (2006) Prospective predictors of body dissatisfaction in adolescent girls and boys: a five-year longitudinal study. Dev Psychol 42, 888-899.

24. Sanchez-Villegas A, Field AE, O'Really EJ et al. (2013) Perceived and actual obesity in childhood and adolescence and risk of adult depression. J Epidemiol Community Health 67, 81-86.

25. Stice E, Presnell K, Shaw H et al. (2005) Psychological and behavioral risk factors for obesity onset in adolescent girls: a prospective study. J Consult Clin Psychol 73, 195-202.

26. Serdula MK, Collins ME, Williamson DF et al. (1993) Weight control practices of US adolescents and adults. Ann Intern Med 119, 667-671.

27. Neumark-Sztainer D \& Hannan PJ (2000) Weight-related behaviours among adolescent girls and boys: results from a national survey. Arch Pediatr Adolesc Med 154, 569-577.
28. Vander Wal JS (2012) Unhealthy weight control behaviours among adolescents. J Health Psychol 17, 110-120.

29. Boutelle K, Neumark-Sztainer D, Story M et al. (2002) Weight control behaviours among obese, overweight and non overweight adolescents. J Pediatr Psychol 27, 531-540.

30. Caradas AA, Lambert EV \& Charlton KE (2001) An ethnic comparison of eating attitudes and associated body image concerns in adolescent of South African schoolgirls. J Hum Nutr Diet 14, 111-120.

31. Wan PL, Kandiah M \& Taib MNM (2004) Body image perception, dietary practices and physical activity of overweight and normal weight Malaysian female adolescents. Malays J Nutr 10, 131-147.

32. Mciza Z, Goedecke JH, Steyn N et al. (2005) Development and validation of instruments measuring body image and body weight dissatisfaction in South African mothers and their daughters. Public Health Nutr 8, 509-519.

33. Xie B, Chou C, Spruijt-Metz D et al. (2006) Weight perception, academic performance and psychological factors in Chinese adolescents. Am J Health Behav 30, 115-124.

34. Sakamaki R, Amamoto R, Mochida Y et al. (2005) A comparative study of food habits and body shape perception of university students in Japan and Korea. Nutr J 4, 31.

35. Srinivasan TN, Suresh TR \& Jayaram V (1998) Emergence of eating disorders in India. Study of eating distress syndrome and development of a screening questionnaire. Int J Soc Psychiatry 44, 189-198.

36. Chugh K \& Puri S (2001) Affluent adolescent girls of Delhi: eating and weight concerns. Br J Nutr 86, 535-542.

37. Bhugra D, Bhui K \& Gupta KR (2000) Bulimic disorders and sociocentric values in north India. Soc Psychiatry Psychiatr Epidemiol 35, 86-93.

38. Stigler MH, Arora M, Dhavan P et al. (2011) Weight-related concerns and weight-control behaviours among overweight adolescents in Delhi, India: a cross-sectional study. Int $J$ Behav Nutr Phys Act 8, 9

39. Augustine LF \& Poojara RH (2003) Prevalence of obesity, weight perceptions and weight control practices among urban college going girls. Indian J Community Med XXVIII, 187-190.

40. World Health Organization (2007) Growth reference data for 5-19 years. http://www.who.int/growthref/en/ (accessed March 2013).

41. Story M, Stevens J, Evans M et al. (2001) Weight loss attempts and attitudes towards body size, eating and physical activity in American Indian children: relationship to weight status and gender. Obes Res 9, 356-363.

42. Viera AJ \& Garrett JM (2005) Understanding inter-observer agreement: the kappa statistic. Fam Med 37, 360-363.

43. Hedley AA, Ogden CL, Johnson CL et al. (2004) Prevalence of overweight and obesity among US children, adolescents and adults, 1999-2002. JAMA 291, 2847-2850.

44. Prentice AM (2006) The emerging epidemic of obesity in developing countries. Int J Epidemiol 35, 93-99.

45. Wu Y (2006) Overweight and obesity in China. Br Med J 333, 362-363.

46. Neumark-Sztainer D, Story M, Hannan PJ et al. (2002) Weight related concerns and behaviours among overweight and non overweight adolescents: implications for preventing weight related disorders. Arch Pediatr Adolesc Med 156, 171-178.

47. Neumark-Sztainer D, Wall M, Guo J et al. (2006) Obesity, disordered eating, and eating disorders in a longitudinal study of adolescents: how do dieters fare 5 years later? $\mathrm{J} \mathrm{Am}$ Diet Assoc 106, 559-568. 